\title{
ANÁLISE DE DESEMPENHO DO CONCRETO COM SUBSTITUIÇÃO DE UMA \\ PORCENTAGEM DO AGREGADO MIÚDO POR RESÍDUOS DE USINAGEM DA
}

\author{
INDÚSTRIA METAL MECÂNICA
}

Thaís Aparecida Zenere ${ }^{1}$

Gabriela Cassol $^{2}$

\section{RESUMO}

Atualmente o mundo vem demonstrando um incentivo grandioso a ações para a sustentabilidade, e o aproveitamento de resíduos industriais na construção civil é uma alternativa para destinar esses materiais, usufruindo dos benefícios que podem oferecer. Buscou-se com este trabalho a substituição de uma porcentagem do agregado miúdo por cavacos de aço na confeç̧ão do concreto. Com isso seria possível diminuir a exploração de recursos naturais como a areia, utilizando resíduos industriais, que se forem descartados de maneira incorreta podem causar impactos ambientais. Foi iniciado este trabalho elaborando o levantamento bibliográfico, para que possa auxiliar no decorrer do mesmo. Este projeto teve como objetivo geral, comparar a resistência mecânica do concreto convencional e do concreto com resíduo de usinagem (cavaco de aço), substituindo uma porcentagem do agregado miúdo pelo resíduo. Os materiais essenciais para realização deste trabalho foram o agregado miúdo, agregado graúdo, água, cimento Portland e o resíduo (cavacos de aço). Sendo assim, para obter os resultados desejados foram realizados os ensaios no Laboratório de Materiais e Solos da UNIARP, como a caracterização dos materiais, granulometria, massa específica dos agregados, massa unitária, absorção de água, trabalhabilidade do concreto e ensaio de resistência a compressão. Todos esses ensaios estão descritos na metodologia deste trabalho, demonstrando as etapas e normas da ABNT que foram seguidas de acordo com cada procedimento, para obter os resultados e alcançar os objetivos propostos.

\footnotetext{
${ }^{1}$ Acadêmica do Curso de Engenharia Civil da Universidade Alto Vale do Rio do Peixe (UNIARP). email: thais.zenere@hotmail.com.

${ }^{2}$ Mestre em Engenharia Civil pela Universidade Estadual Paulista (UNESP) e docente do Curso de Engenharia Civil da Universidade Alto Vale do Rio do Peixe (UNIARP). email: gabriela.cassol@uniarp.edu.br.
} 
Palavras-Chave: Concreto. Resíduo. Cavacos de aço.

\section{ABSTRACT}

Nowadays the world has been demonstrating a great incentive to actions for sustainability, and the use of industrial waste in construction is an alternative to allocate these materials, taking advantage of the benefits they can offer. The aim of this work is to substitute a percentage of the small aggregate for steel chips in the confection of the concrete. This would reduce the exploitation of natural resources such as sand, using industrial waste, which if discarded incorrectly can cause environmental impacts. This work was started by preparing the bibliographical survey, so that it can help in the course of it. This project aims to compare the mechanical strength of conventional concrete and concrete with machining residue (steel chip), replacing a percentage of the small aggregate with the residue. The essential materials for this work were the small aggregate, aggregate, water, Portland cement and the residue (steel chips). In order to obtain the desired results, the tests were carried out in the Materials and Soils Laboratory of UNIARP, such as the characterization of the materials, granulometry, specific mass of the aggregates, unit mass, water absorption, concrete workability and compressive strength test . All these tests are described in the methodology of this work, demonstrating the steps and norms of the ABNT that were followed according to each procedure.

Keywords: Concrete. Residue. Steel shavings.

\section{INTRODUÇÃO}

Com o desenvolvimento das empresas na última década, as preocupações com novas alternativas para a sustentabilidade e o reaproveitamento de materiais em benefício ao meio ambiente, se tornou necessário. Como a indústria é responsável pela geração acelerada de resíduos, e o concreto está presente na maioria das obras do Brasil, buscou-se com este trabalho a utilização de resíduos de cavacos de aço na confecção do concreto, para obter possíveis vantagens com a substituição de uma porcentagem do agregado miúdo (areia) pelo resíduo.

Cavaco é uma porção de material, retirada pelas ferramentas empregadas na usinagem para obter geometria, dimensões e acabamento final da peça (MACHADO et al., 2015). Sendo assim, se tornou o principal resíduo dos processos de fabricação da indústria metal mecânica, podendo ser obtido facilmente em grandes volumes em todas as empresas deste ramo. 
Os processos de usinagem envolvem operações de corte que permitem remover excessos de um material bruto com auxílio de uma ferramenta ou máquina resultando em uma peça pronta (SOUZA, 2011). Após este processo, os resíduos são designados para reciclagem, pois não possuem mais utilidade nas empresas. Porém se forem descartados de uma forma inadequada, podem ser prejudiciais ao meio ambiente.

Dessa maneira, a aplicação de cavacos de aço na produção do concreto pode se tornar uma opção para destinar corretamente este tipo de resíduo industrial com menor custos e obter a redução da utilização de recursos naturais na construção civil. A exploração da areia, pode acarretar muitas vezes impactos ambientais, porque este material é retirado da natureza, geralmente encontrado no fundo de rios. E a diminuição desta extração, se torna uma alternativa sustentável.

Este trabalho aborda o desenvolvimento de um concreto com a substituição parcial da areia por cavacos de aço, sendo que este resíduo possui vários materiais que o compõe, porém o mais amplamente empregado é o aço SAE (Sociedade dos Engenheiros Automotivos dos EUA) 1020. Com isso, será possível manter ou aumentar a resistência do concreto através da substituição de uma porcentagem do agregado miúdo por cavacos de aço?

Portanto, o que justifica este trabalho é oferecer os conhecimentos adquiridos para as empresas de construção civil, obtidos no decorrer das pesquisas e ensaios em laboratório. E demostrar que é possível utilizar o cavaco de aço da indústria metal mecânica, contribuindo no aproveitamento de resíduos industriais, tornando-se uma alternativa mais econômica para sua destinação e ajudando a preservar recursos naturais.

O objetivo geral deste trabalho é comparar a resistência mecânica do concreto convencional e do concreto com resíduo (cavaco de aço), substituindo uma porcentagem do agregado miúdo pelo resíduo. Logo, os objetivos específicos são:

a) Desenvolver o referencial bibliográfico;

b) Caracterizar os materiais (agregado miúdo e resíduo de cavaco de aço);

c) Determinar a dosagem do concreto com e sem o resíduo;

d) Realizar ensaios no estado fresco;

e) Efetuar ensaios no estado endurecido. 
Neste contexto, a metodologia empregada foi o estudo envolvendo a fundamentação teórica com a análise experimental no Laboratório de Materiais e Solos da Universidade Alto Vale do Rio do Peixe, UNIARP. Tentando comprovar a importância do aproveitamento de materiais provenientes dos resquícios da indústria. Desta forma, pode ser demonstrado que é possível poupar os recursos naturais empregados na construção civil conseguindo manter a resistência mecânica do concreto.

\section{DESENVOLVIMENTO}

\subsection{USINAGEM}

A usinagem é a transformação da matéria-prima em produto através da remoção de material em forma de cavacos (SANTOS; SALES, 2007). Para obter a forma, dimensões e acabamento final da peça, é realizado ações para remover o material necessário, gerando cavaco como seu resíduo.

\subsubsection{Cavaco de Aço}

No decorrer do processo de usinagem, uma nova forma e acabamento são gerados na peça, através da retirada de material no formato de cavaco. Desta forma os cavacos são classificados de diversas maneiras, podem ser denominados contínuos, descontínuos e segmentados (MACHADO et al., 2015).

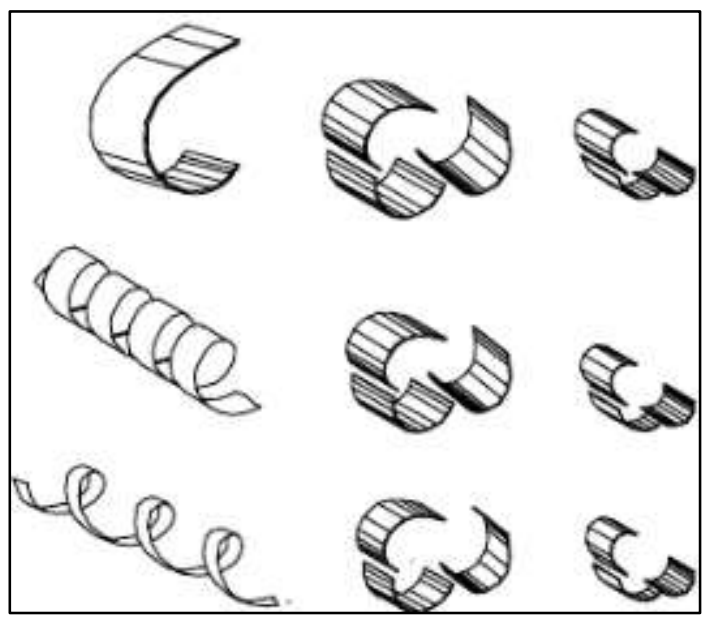

Figura 1 - Formatos de cavaco 
Fonte: Santos e Sales (2007)

a) Cavacos contínuos: É o resultado da usinagem de materiais dúcteis como aços de baixa liga, cobre, alumínio. Por isso usinando um material dúctil forma cavacos mais longos e contínuos (SOUZA, 2011);

b) Cavacos descontínuos: Resulta da usinagem de materiais frágeis, como bronze e ferros fundidos (SANTOS; SALES, 2007);

c) Cavacos segmentados: Caracterizam-se por ter grandes deformações continuadas (MACHADO et al., 2015).

\subsection{RESÍDUOS INDUSTRIAIS}

Os resíduos industriais são gerados por ramos variados de indústrias. Esse material descartável para as empresas, deve obter um destino apropriado, pois pode acarretar riscos para o meio ambiente (KRAEMER, 2017).

\subsection{CONCRETO}

O processo de escolha dos materiais é feito para que obtenha um concreto o mais econômico possível e que atenda as propriedades mínimas, especialmente a consistência, durabilidade e a resistência. A qualidade do concreto fresco e endurecido depende dos aspectos dos materiais que serão utilizados, por isso devem ser componentes adequados (NEVILLE, 2016).

\subsubsection{Trabalhabilidade}

O teste de abatimento do concreto é realizado para notar a trabalhabilidade da massa e observar se atende a consistência desejada. E os procedimentos para este ensaio deve ser seguida conforme a NBR NM 67 (ABNT, 1998).

\subsection{METODOLOGIA E MATERIAL}

\subsubsection{Material}

Para preparar o concreto, é necessária uma mistura de todos os seus 
componentes com a adição ou não de outros materiais. Logo abaixo demonstra os materiais empregados:
a) Cimento Portland;
b) Agregados miúdo natural;
c) Agregado miúdo artificial (Cavaco de aço);
d) Agregado graúdo natural;
e) Água de amassamento.

\subsubsection{Cimento Portland}

Atualmente pode ser encontrado diversos tipos de cimentos com diferentes características, mas o que foi utilizado neste trabalho referiu-se ao cimento Portland CP || Z - 32, que pode ser encontrado com facilidade, sendo empregado em obras diversificadas.

Segundo a NBR 11578 (ABNT, 1997), este tipo de cimento CP II-Z, é composto por limites fixos, com adição de material pozolânico de $6 \%$ á $14 \%$, clínquer mais sulfatos de cálcio de $94 \%$ á $76 \%$ e material carbonático de $0 \%$ á $10 \%$. Podendo ter uma resistência de 25MPa, 32MPa ou 40MPa. E não deve ser aceito em sacos rasgados ou molhados.

\subsubsection{Agregado miúdo}

Uma massa consistente deve conter um agregado miúdo livre de impurezas e com aspecto apropriado para sua utilização em uma massa. O agregado miúdo utilizado foi a areia média. É necessário realizar a caracterização dos agregados para obter um concreto corretamente dosado e ter conhecimento dos aspectos do mesmo. Por isso, foi efetuado esses procedimentos, de acordo com as normas a seguir:

a) NBR NM 248: Agregados - Determinação da composição granulométrica (ABNT, 2003);

b) NBR NM 45: Agregados - Determinação da massa unitária e do volume de vazios (ABNT, 2006);

c) NBR NM 30: Agregado miúdo - Determinação da absorção de água 
(ABNT, 2001);

d) NBR NM 52: Agregado miúdo - Determinação da massa especifica e massa especifica aparente (ABNT, 2009).

\subsubsection{Agregado graúdo}

O agregado graúdo utilizado neste trabalho foi a brita 1, esse material tem interferência no resultado final do concreto, dependendo da resistência mecânica que deseja alcançar, sua granulometria é determinada de acordo com a necessidade da massa.

Por tanto, foi efetuado os ensaios em laboratório determinando sua composição granulométrica, sua massa e volume, seguindo de acordo com as normas abaixo:

a) NBR NM 248: Agregados - Determinação da composição granulométrica (ABNT, 2003);

b) NBR NM 45: Agregados - Determinação da massa unitária e do volume de vazios (ABNT, 2006);

c) NBR NM 46: Agregados - Determinação do material fino que passa através da peneira 75 um, por lavagem (ABNT, 2003);

d) NBR NM 53: Agregado graúdo - Determinação de massa específica, massa específica aparente e absorção de água (ABNT, 2009).

\subsubsection{Resíduo de cavaco}

O processo de fabricação da indústria Metal Mecânica, envolve máquinas para fazer o corte e modelar as peças de acordo com a necessidade. A usinagem envolve diversos procedimentos, e um deles é o Serramento.

O resíduo de cavaco de aço que foi utilizado no decorrer deste trabalho, é proveniente do processo convencional de Serramento. Na Figura 2 a seguir, pode ser notado como é o formato e dimensão do resíduo que foi inserido no concreto. 


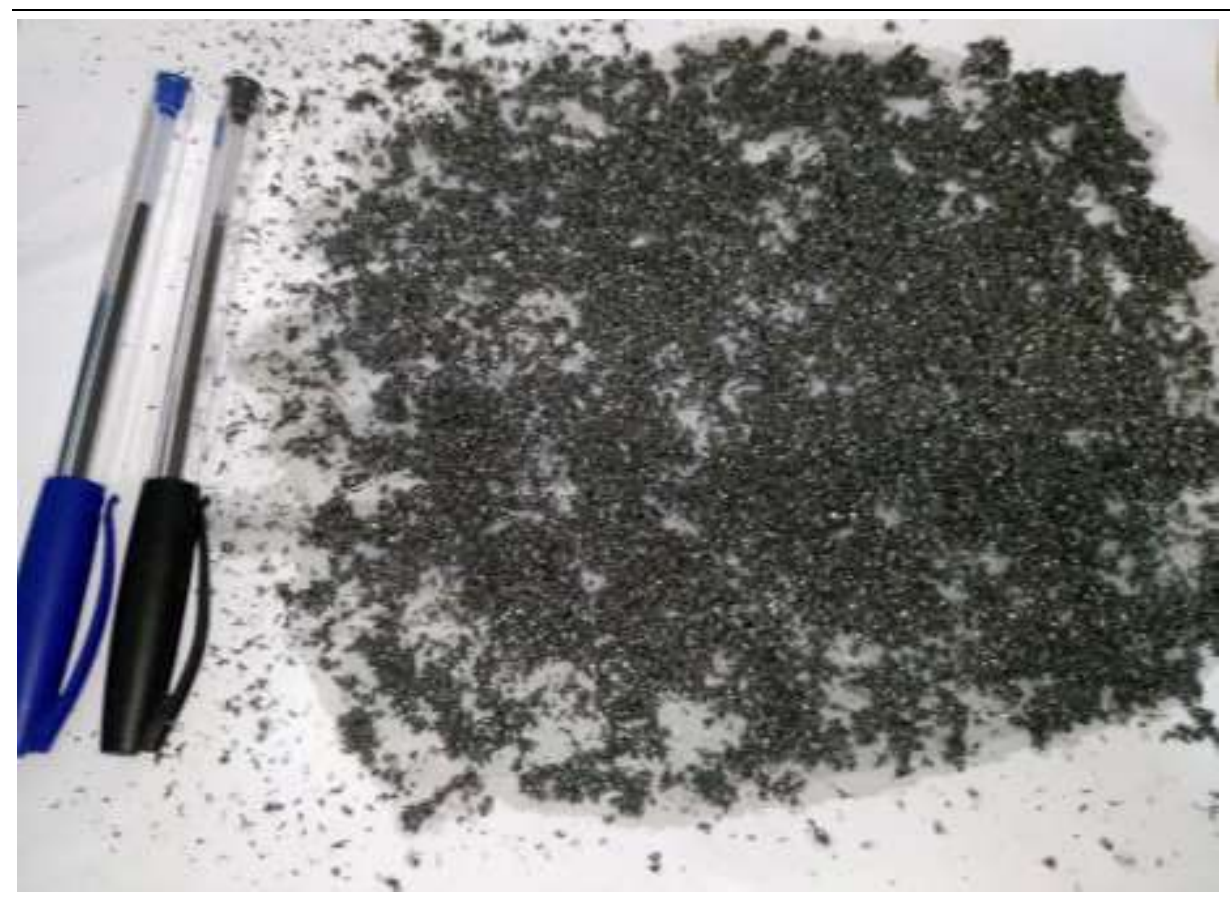

Figura 2 - Resíduo (Cavaco de aço)

Fonte: O próprio autor 


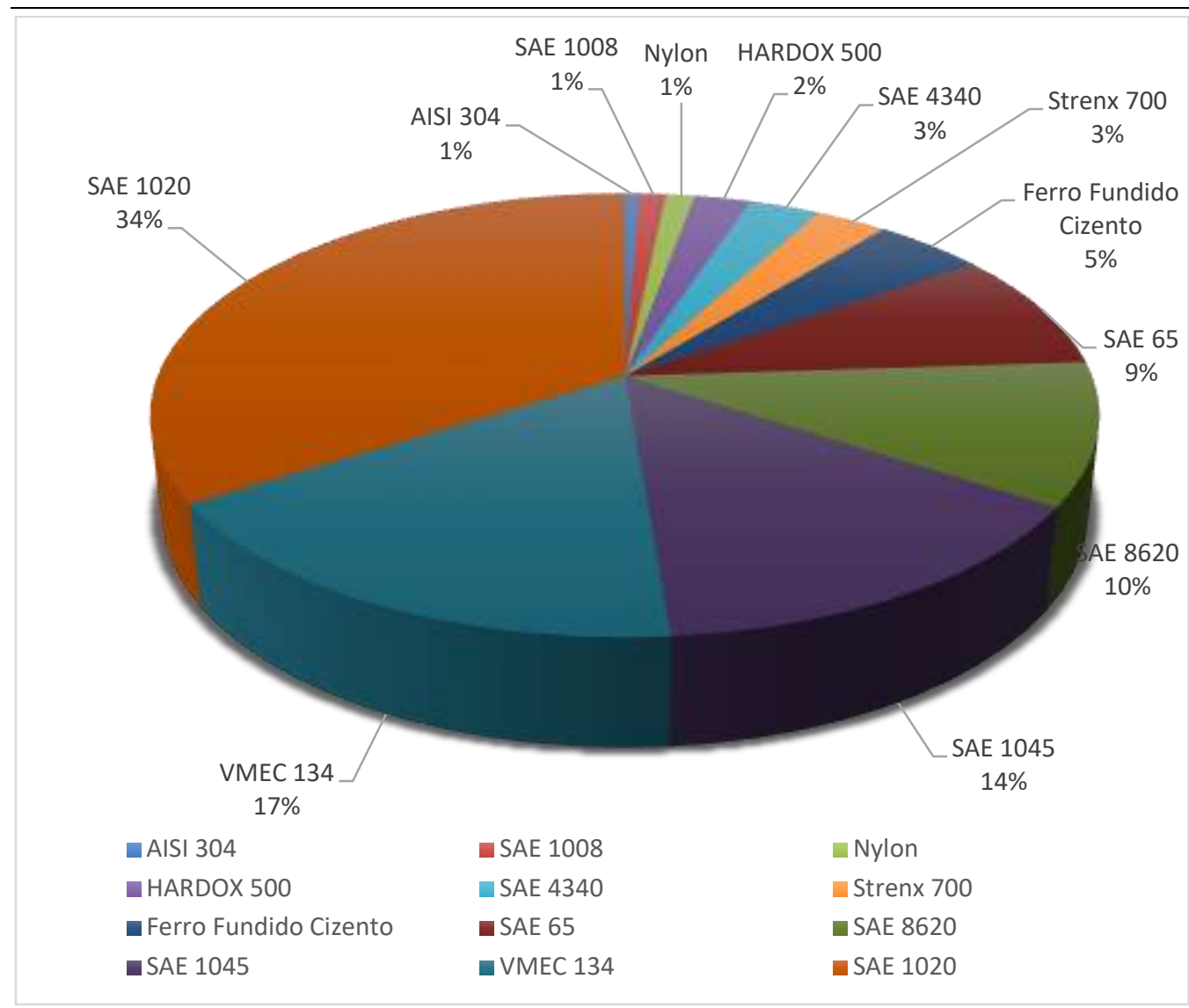

Gráfico 1 - Porcentagem de aços presentes no resíduo de usinagem

Fonte: O próprio autor

\subsubsection{5 Água de amassamento}

Como os outros componentes do concreto, a água tem enorme importância na confecção do concreto e sua quantidade tem fator essencial na determinação final da resistência do concreto. Por isso, foi adicionado a quantidade de água necessária, visivelmente analisado, e definido referente ao Slump Test apresentado.

Neste trabalho, foi usada a água proveniente do poço artesiano que abastece as instalações da UNIARP.

\subsection{APRESENTAÇÃO, ANÁLISE DOS DADOS E RESULTADOS}

Com os ensaios realizados de granulometria, massa específica, massa unitária e absorção de água, foi possível classificar o agregado miúdo, agregado graúdo e os cavacos de aço utilizados posteriormente para confeccionar o concreto. 
Abaixo na Tabela 1, pode ser analisado as características apresentadas pelos materiais.

Tabela 2. Características do agregado miúdo, agregado graúdo e cavacos de aço

\begin{tabular}{llll}
\hline & Agregado miúdo & Cavacos de aço & Agregado graúdo \\
\hline Granulometria & Média & Grossa & Brita 1 \\
\hline Módulo de finura & 3,03 & 4,68 & 1,27 \\
\hline Diâmetro máximo $(\mathrm{mm})$ & 2,00 & 4,75 & 9,5 \\
\hline Massa específica $\left(\mathrm{g} / \mathrm{cm}^{3}\right)$ & 2,64 & 14,13 & 2,12 \\
\hline Absorção de água $(\%)$ & 0,33 & 15,4 & 7,31 \\
\hline Massa unitária $\left(\mathrm{kg} / \mathrm{m}^{3}\right)$ & 1598,75 & 1015,5 & 1541,62 \\
\hline
\end{tabular}

Fonte: O próprio autor

\subsubsection{Definição do Traço do Concreto}

Posteriormente aos ensaios de caracterização do agregado miúdo, graúdo e resíduo de cavaco de aço, realizou-se o estudo de dosagem. Primeiramente foi calculado a quantidade específica de cada material necessário para confeccionar o concreto.

Inicialmente foram confeccionados três traços de concreto para obtenção do traço padrão, sendo escolhido o traço que a apresentou a maior resistência a compressão:

a) Traço 1:3,5 (cimento: massa total de agregados);

b) Traço 1:5 (cimento: massa total de agregados);

c) Traço 1:6,5 (cimento: massa total de agregados).

No dia 01 de setembro de 2017, foram confeccionados os três traços de concreto convencional, sendo três corpos-de-prova por traço como é possível ver na Figura 3 a seguir. 


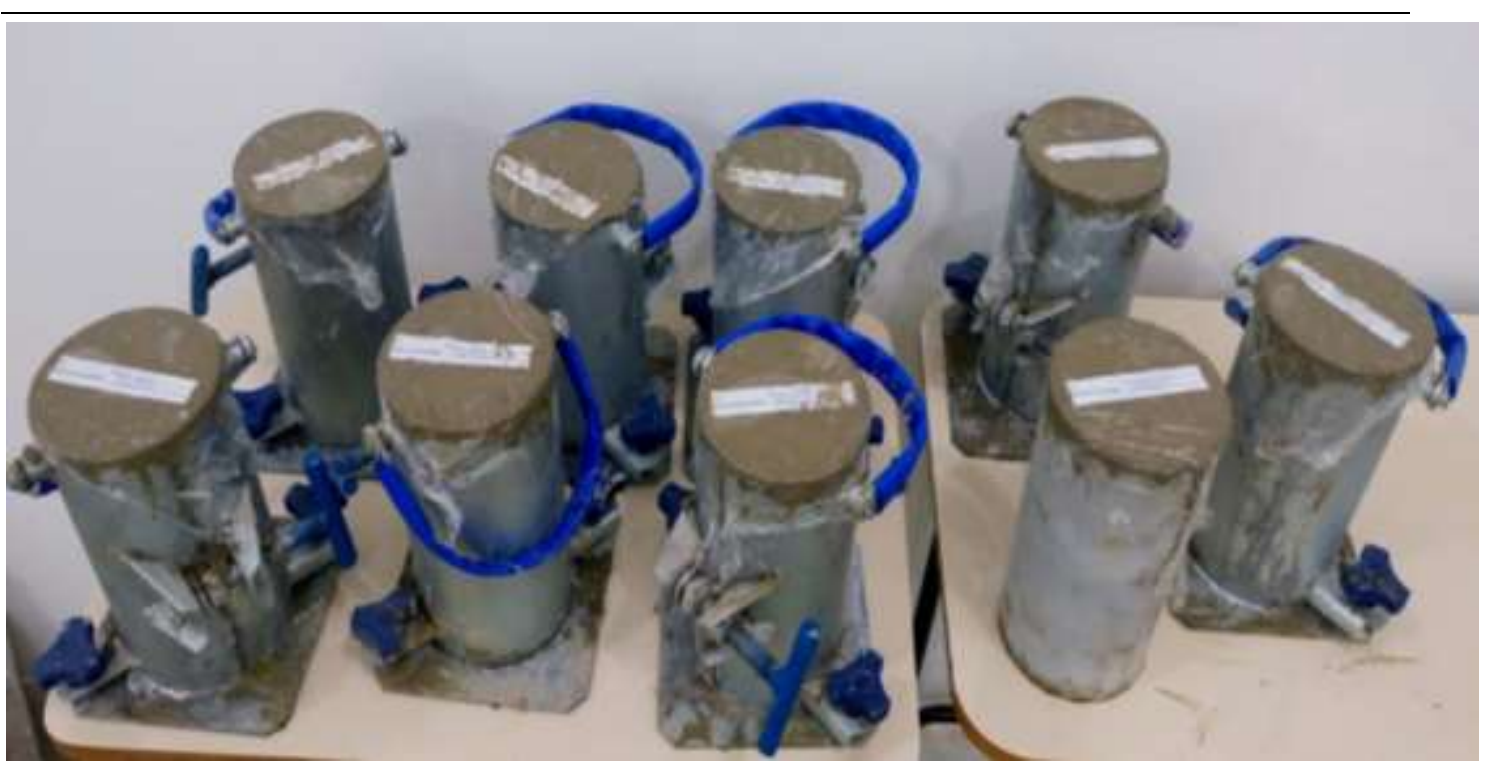

Figura 3 - Corpos-de-prova dos três traços de concreto

Fonte: O próprio autor

O Slump Test utilizado foi $6 \pm 1 \mathrm{~cm}$. Abaixo na Tabela 2, pode ser observado o Slump que cada traço apresentou, a quantidade de água adicionada e a quantidade de material utilizado.

Tabela 3. Traços 1:3,5, 1:5 e 1:6,5 e as quantidades de materiais inseridos

\begin{tabular}{llllll}
\hline Traço & $\begin{array}{l}\text { Slump Test } \\
(\mathrm{cm})\end{array}$ & $\begin{array}{l}\text { Cimento Portland } \\
(\mathrm{Kg})\end{array}$ & $\begin{array}{l}\text { Agregado miúdo } \\
(\mathrm{Kg})\end{array}$ & $\begin{array}{l}\text { Agregado graúdo } \\
(\mathrm{Kg})\end{array}$ & $\begin{array}{l}\text { Água } \\
(\mathrm{Kg})\end{array}$ \\
\hline $1: 3,5$ & 6 & 4,44 & 5,75 & 9,8 & $2,57 \mathrm{~kg}$ \\
\hline $1: 5$ & 5 & 3,33 & 6,87 & 9,8 & $2,08 \mathrm{~kg}$ \\
\hline $1: 6,5$ & 5 & 2,67 & 7,53 & 9,8 & $1,9 \mathrm{~kg}$ \\
\hline
\end{tabular}

Após o período de 7 dias, foi realizado o ensaio de resistência à compressão dos três traços, onde é possível notar a resistência dos melhores corpos-de-prova rompidos e a resistência média deles, podendo ser observada na Tabela 3.

Tabela 4. Resistência à compressão dos três traços

\begin{tabular}{lll}
\hline Traço & Resistência a compressão fck (MPa) & $\begin{array}{l}\text { Resistência à compressão média fck } \\
(\mathrm{MPa})\end{array}$ \\
\hline $1: 3,5$ & 24,51 & 22,77 \\
\cline { 2 - 3 } $1: 5$ & 21,03 & 13,12 \\
\hline
\end{tabular}




\begin{tabular}{ll}
\hline \hline \multirow{2}{*}{$1: 6,5$} & 10,72 \\
\cline { 2 - 2 } & 9,58 \\
\hline
\end{tabular}

A partir dos resultados do ensaio de resistência à compressão, definiu-se que o traço 1:3,5 será utilizado como padrão para a realização da substituição da areia pelo resíduo de cavaco de aço, pois apresentou resistência a compressão média de 22,77 Mpa aos 7 dias.

E a seguir na Figura 4, pode ser notado o ensaio de resistência a compressão do corpo-de-prova com traço 1:3,5.

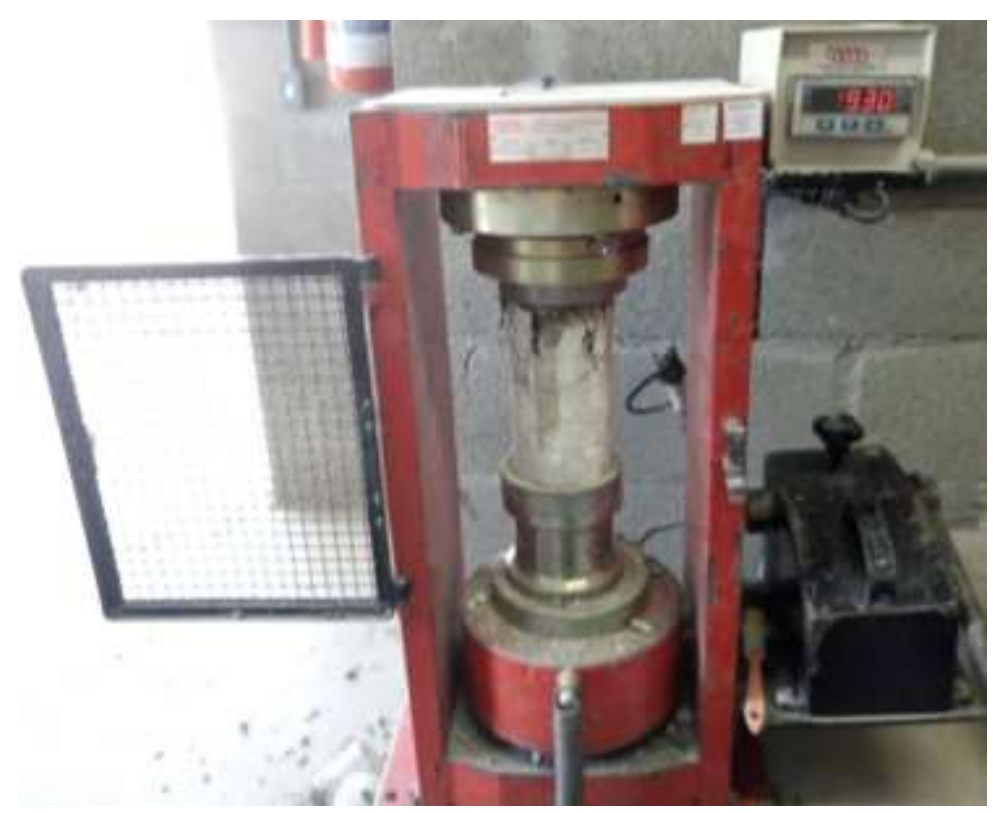

Figura 4 - Ensaio de compressão

Fonte: O próprio autor

\subsubsection{Confecção do Concreto Convencional}

Para ser possível comparar o concreto convencional com o concreto com resíduos de usinagem e conseguir realizar o objetivo geral proposto deste trabalho, foi necessário começar a preparação pelo concreto convencional.

Primeiramente foram definidos a quantia necessária de cada material, utilizando traço já definido de 1:3,5. Na Tabela 4 a seguir, pode ser notado os materiais e suas quantidades inseridas na dosagem do concreto, para preparar nove 
corpos-de-prova, sendo que foram rompidos aos 7, 14 e 28 dias.

Tabela 5. Quantidade de materiais utilizados no concreto convencional e o Slump Test apresentado

\begin{tabular}{lllllc}
\hline Traço & $\begin{array}{l}\text { Slump Test } \\
(\mathrm{cm})\end{array}$ & $\begin{array}{l}\text { Cimento Portland } \\
(\mathrm{Kg})\end{array}$ & $\begin{array}{l}\text { Agregado miúdo } \\
(\mathrm{Kg})\end{array}$ & $\begin{array}{l}\text { Agregado } \\
\text { graúdo }(\mathrm{Kg})\end{array}$ & Água $(\mathrm{Kg})$ \\
\hline $1: 3,5$ & 6,2 & 11,11 & 14,39 & 24,5 & $4,93 \mathrm{~kg}$ \\
\hline
\end{tabular}

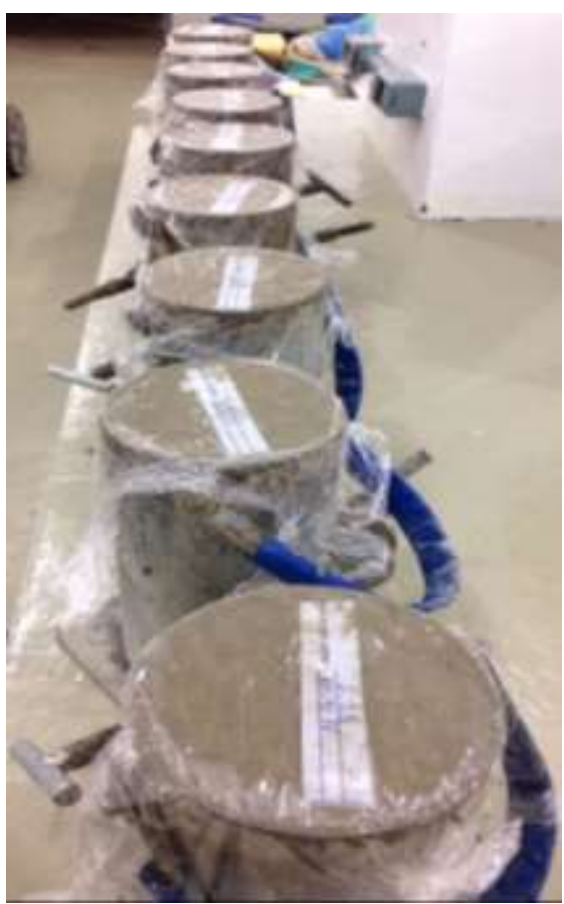

Figura 5 - Corpos-de-prova do concreto convencional

Fonte: O próprio autor

Após os períodos de dias conforme prescrito em norma, foi realizado o rompimento dos corpos-de-prova para obter os valores de resistência à compressão. A Tabela 5 demonstra os resultados apresentados.

Tabela 6. Resistência à compressão do concreto convencional aos 7,14 e 28 dias

\begin{tabular}{|c|c|c|c|c|c|}
\hline $\begin{array}{l}\text { Resistência à } \\
\text { compressão aos } 7 \\
\text { dias (MPa) }\end{array}$ & Média & $\begin{array}{l}\text { Resistência à } \\
\text { compressão aos } \\
14 \text { dias (MPa) }\end{array}$ & Média & $\begin{array}{l}\text { Resistência à } \\
\text { compressão aos } \\
28 \text { dias (MPa) }\end{array}$ & Média \\
\hline 29,46 & \multirow{3}{*}{22,79} & 34,58 & \multirow{3}{*}{31,15} & 42,33 & \multirow{3}{*}{40,40} \\
\hline 27,69 & & 33,26 & & 39,97 & \\
\hline 11,24 & & 25,60 & & 38,90 & \\
\hline
\end{tabular}


2.5.2.1 Confecção do concreto com substituição do agregado miúdo pelo cavaco de aço

Com o traço já determinado de 1:3,5, foi possível iniciar a confecção do concreto inserindo o resíduo de cavaco de aço. Foram definidas as porcentagens de substituição do agregado miúdo pelo resíduo de usinagem em 10 \%, 15\%, 20\%.

\subsubsection{Concreto com substituição de $20 \%$ do agregado miúdo}

Iniciando pela substituição de uma porcentagem de $20 \%$ do agregado miúdo pelo cavaco de aço, foi estipulado e calculado a quantidade necessária de cada material para confeccionar $50 \mathrm{~kg}$ de concreto. Abaixo na Tabela 6 pode ser possível ver esses dados.

Tabela 7. Quantidade de materiais utilizados no concreto com substituição de $20 \%$ e o Slump apresentado

\begin{tabular}{llllll}
\hline $\begin{array}{l}\text { Slump Test } \\
(\mathrm{cm})\end{array}$ & $\begin{array}{l}\text { Cimento Portland } \\
(\mathrm{Kg})\end{array}$ & $\begin{array}{l}\text { Agregado } \\
\text { miúdo }(\mathrm{Kg})\end{array}$ & $\begin{array}{l}\text { Agregado } \\
\text { graúdo }(\mathrm{Kg})\end{array}$ & $\begin{array}{l}\text { Água } \\
(\mathrm{Kg})\end{array}$ & $\begin{array}{l}\text { Cavaco de } \\
\text { aço }(\mathrm{Kg})\end{array}$ \\
\hline 3,0 & 11,11 & 11,50 & 24,5 & 5,43 & 2,88 \\
\hline
\end{tabular}

No Slump Test o concreto chegou a um valor não esperado, já havia sido adicionado água ao suficiente e o concreto não cedeu o desejado, portanto o Slump alcançado com $20 \%$ de substituição do agregado miúdo pelo resíduo foi de apenas 3 centímetros. 


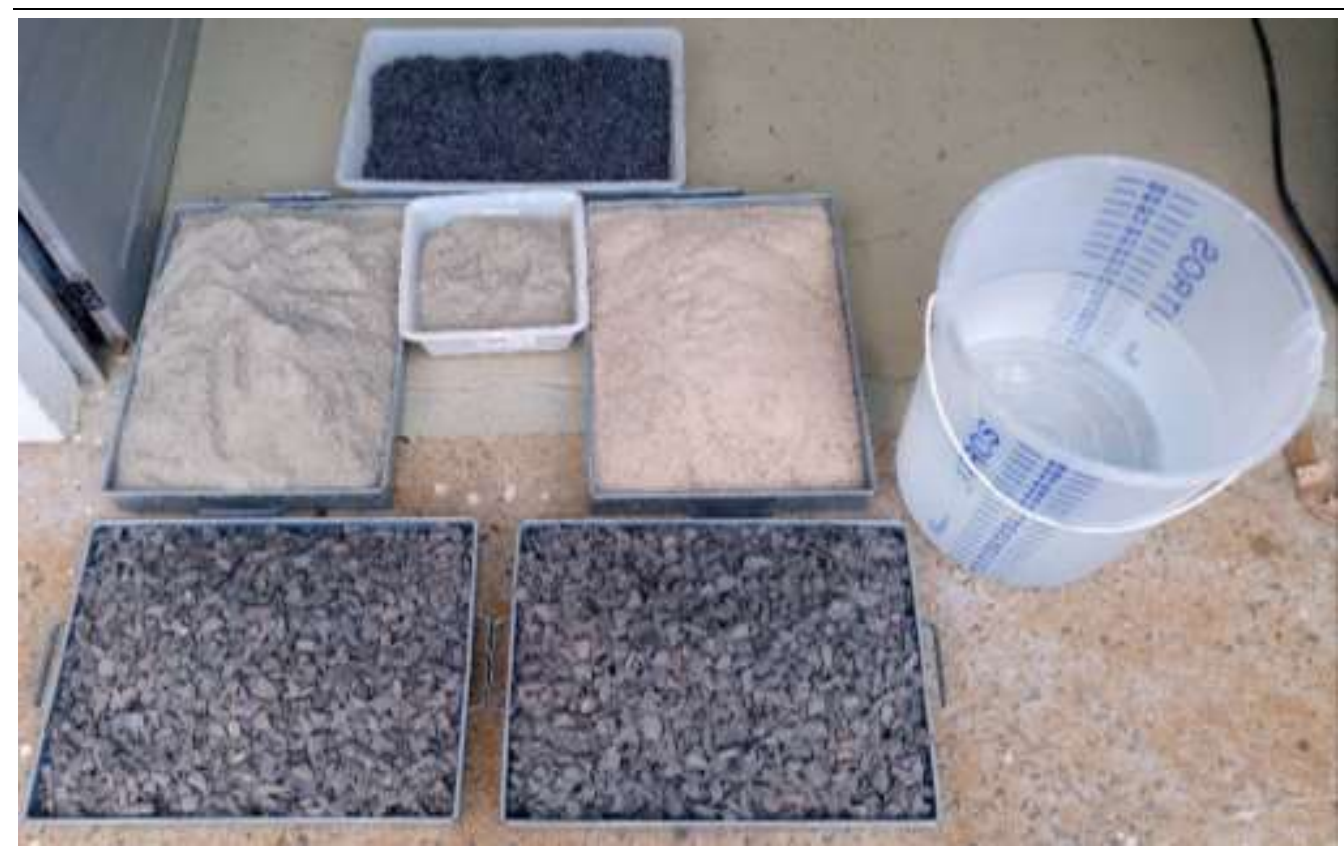

Figura 6 - Materiais utilizados no concreto com cavacos de aço Fonte: O próprio autor

A seguir na Tabela 7 pode ser notado a resistência a compressão que o concreto com substituição de $20 \%$ do agregado miúdo pelo cavaco de aço demonstrou no período de 7,14 e 28 dias.

Tabela 8. Resistência à compressão do concreto com 20\% de substituição aos 7,14 e 28 dias

\begin{tabular}{|c|c|c|c|c|c|}
\hline $\begin{array}{l}\text { Resistência à } \\
\text { compressão aos } 7 \\
\text { dias (MPa) }\end{array}$ & Média & $\begin{array}{l}\text { Resistência à } \\
\text { compressão aos } \\
14 \text { dias (MPa) }\end{array}$ & Média & $\begin{array}{l}\text { Resistência à } \\
\text { compressão aos } \\
28 \text { dias (MPa) }\end{array}$ & Média \\
\hline 10,22 & \multirow{3}{*}{10,17} & 12,73 & \multirow{3}{*}{13,45} & 16,70 & \multirow{3}{*}{18,03} \\
\hline 10,26 & & 14,44 & & 18,79 & \\
\hline 10,05 & & 13,17 & & 18,60 & \\
\hline
\end{tabular}

\subsubsection{Concreto com substituição de $15 \%$ do agregado miúdo}

Com a substituição de uma porcentagem de $15 \%$ do agregado miúdo pelo cavaco de aço, foi calculado a quantidade necessária de cada material para confeccionar $45 \mathrm{~kg}$ de concreto. Abaixo na Tabela 8 pode ser observado esses dados. 
Tabela 9. Quantidade de materiais utilizados no concreto com substituição de 15\% e o Slump apresentado

\begin{tabular}{llllll}
\hline $\begin{array}{l}\text { Slump Test } \\
(\mathrm{cm})\end{array}$ & $\begin{array}{l}\text { Cimento Portland } \\
(\mathrm{Kg})\end{array}$ & $\begin{array}{l}\text { Agregado } \\
\text { miúdo }(\mathrm{Kg})\end{array}$ & $\begin{array}{l}\text { Agregado } \\
\text { graúdo }(\mathrm{Kg})\end{array}$ & $\begin{array}{l}\text { Água } \\
(\mathrm{Kg})\end{array}$ & $\begin{array}{l}\text { Cavaco de } \\
\text { aço }(\mathrm{Kg})\end{array}$ \\
\hline 5,3 & 10 & 11 & 22,05 & 4,76 & 1,94 \\
\hline
\end{tabular}

Abaixo na Tabela 9 é possível notar a resistência a compressão que o concreto com substituição de $15 \%$ do agregado miúdo pelo cavaco de aço apresentou no período de 7,14 e 28 dias.

Tabela 10. Resistência à compressão do concreto com 15\% de substituição aos 7,14 e 28 dias

\begin{tabular}{|c|c|c|c|c|c|}
\hline $\begin{array}{l}\text { Resistência à } \\
\text { compressão aos } 7 \\
\text { dias (MPa) }\end{array}$ & Média & $\begin{array}{l}\text { Resistência à } \\
\text { compressão aos } \\
14 \text { dias (MPa) }\end{array}$ & Média & $\begin{array}{l}\text { Resistência à } \\
\text { compressão aos } \\
28 \text { dias (MPa) }\end{array}$ & Média \\
\hline 32,60 & \multirow{3}{*}{32,09} & 31,13 & \multirow{3}{*}{34,73} & 39,28 & \multirow{3}{*}{40,01} \\
\hline 31,79 & & 36,37 & & 39,96 & \\
\hline 31,89 & & 36,70 & & 40,78 & \\
\hline
\end{tabular}

\subsubsection{Concreto com substituição de $10 \%$ do agregado miúdo}

Com a substituição de uma porcentagem de $10 \%$ do agregado miúdo pelo cavaco de aço, foi estimado a quantidade necessária de cada material para confeccionar $45 \mathrm{~kg}$ de concreto. Abaixo na Tabela 10 pode ser possível ver esses dados.

Tabela 11.Quantidade de materiais utilizados no concreto com substituição de $10 \%$ e o Slump apresentado

\begin{tabular}{llllll}
\hline $\begin{array}{l}\text { Slump Test } \\
(\mathrm{cm})\end{array}$ & $\begin{array}{l}\text { Cimento Portland } \\
(\mathrm{Kg})\end{array}$ & $\begin{array}{l}\text { Agregado } \\
\text { miúdo }(\mathrm{Kg})\end{array}$ & $\begin{array}{l}\text { Agregado } \\
\text { graúdo }(\mathrm{Kg})\end{array}$ & $\begin{array}{l}\text { Água } \\
(\mathrm{Kg})\end{array}$ & $\begin{array}{l}\text { Cavaco de } \\
\text { aço }(\mathrm{Kg})\end{array}$ \\
\hline 4,9 & 10 & 11,65 & 22,05 & 4,95 & 1,29 \\
\hline
\end{tabular}

Abaixo na Tabela 11 pode ser visto a resistência à compressão que o concreto com substituição de $10 \%$ do agregado miúdo pelo cavaco de aço apresentou no período de 7,14 e 28 dias. 


\begin{tabular}{|c|c|c|c|c|c|}
\hline $\begin{array}{l}\text { Resistência à } \\
\text { compressão aos } 7 \\
\text { dias (MPa) }\end{array}$ & Média & $\begin{array}{l}\text { Resistência à } \\
\text { compressão aos } \\
14 \text { dias (MPa) }\end{array}$ & Média & $\begin{array}{l}\text { Resistência à } \\
\text { compressão aos } \\
28 \text { dias (MPa) }\end{array}$ & Média \\
\hline 34,03 & \multirow{3}{*}{35,27} & 37,51 & \multirow{3}{*}{37,01} & 44,37 & \multirow{3}{*}{40,50} \\
\hline 35,80 & & 36,66 & & 42,67 & \\
\hline 35,99 & & 36,86 & & 34,47 & \\
\hline
\end{tabular}

\subsubsection{Comparativo do Concreto Tradicional com o Concreto com Cavacos de Aço}

Tabela 13.Comparação do concreto convencional e concreto com cavacos de aço aos 28 dias

\begin{tabular}{llll}
\hline & $\begin{array}{l}\text { Resistência à } \\
\text { compressão aos 7 } \\
\text { dias (MPa) }\end{array}$ & $\begin{array}{l}\text { Resistência à } \\
\text { compressão aos 14 } \\
\text { dias (MPa) }\end{array}$ & $\begin{array}{l}\text { Resistência à } \\
\text { compressão aos 28 } \\
\text { dias (MPa) }\end{array}$ \\
\hline Concreto tradicional & 22,79 & 31,15 & 40,40 \\
\hline $\begin{array}{l}\text { Concreto com 10\% de } \\
\text { substituição }\end{array}$ & 35,27 & 37,01 & 40,50 \\
\hline $\begin{array}{l}\text { Concreto com 15\% de } \\
\text { substituição }\end{array}$ & 32,09 & 34,73 & 40,01 \\
\hline $\begin{array}{l}\text { Concreto com 20\% de } \\
\text { substituição }\end{array}$ & 10,17 & 13,45 & 18,03 \\
\hline
\end{tabular}

Gráfico 2 - Comparação do concreto convencional e concreto com cavacos de aço

\section{Comparativo do concreto convencional com o concreto com cavacos de aço}

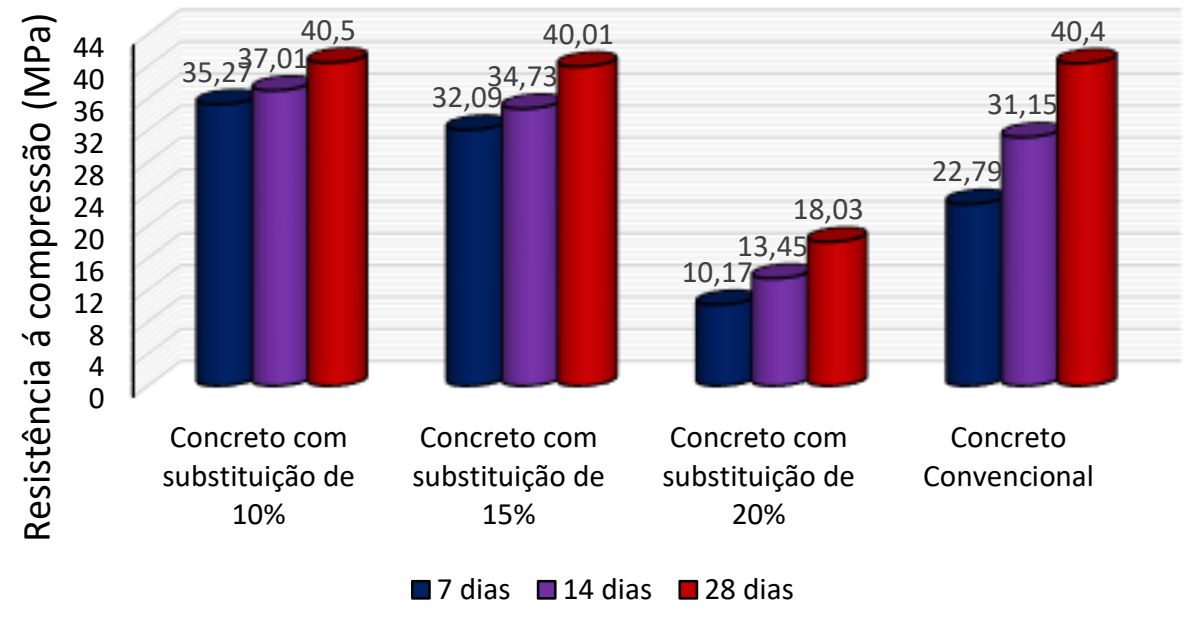

Ignis | Caçador | v.6 | n.3 | p. 93-112 | set./dez. 2017 
Por tanto, através dos resultados apresentados, pode ser concluído que até $15 \%$ o agregado miúdo pode ser substituído pelos cavacos de aço, sem defasar a resistência à compressão do concreto.

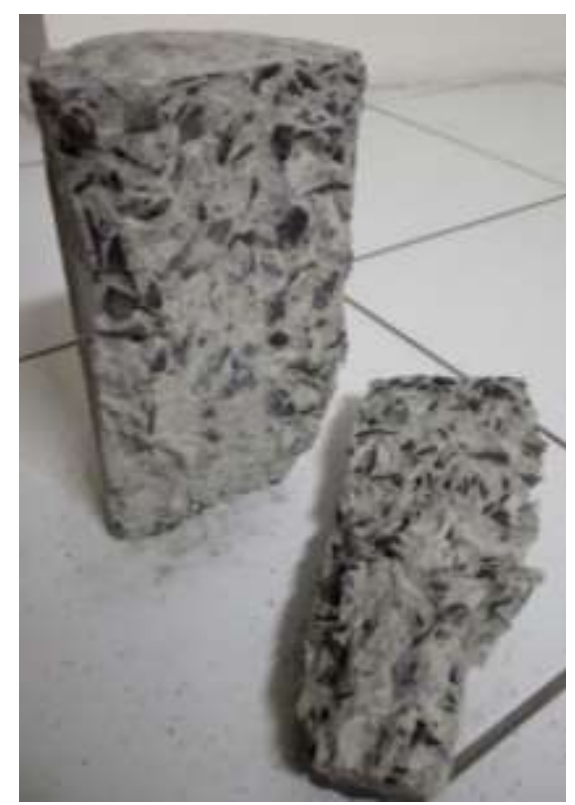

Figura 7 - Corpo-de-prova rompido aos 28 dias com 15 \% de substituição Fonte: O próprio autor

E a substituição de $20 \%$, demonstrou resistência a compressão abaixo do que o concreto convencional, não sendo indicado a utilização desta porcentagem.

\section{CONCLUSÃO}

Atualmente o consumo de produtos industriais está cada vez mais acelerado, gerando inúmeros resíduos que precisam ser destinados e aproveitados da melhor maneira possível. Como o concreto é um material pertinente e está sendo utilizado na maioria das obras no Brasil, acrescentar um resíduo industrial na sua confecção e alcançar bons resultados com a aplicação deste material, se tornou um tema interessante a ser estudado, buscando a melhoria do concreto com resíduos industriais.

Nos dias atuais, o mundo está cada vez mais preocupado com a sustentabilidade, sempre investigando e examinando novas alternativas. Com a 
substituição de uma porcentagem do agregado miúdo por cavacos de aço, proveniente do processo de serramento, uma forma de usinagem, pode ser obtido o aproveitamento de resquícios industriais de forma simples e com menor custos. Outro benefício ao usar este material é a capacidade de poupar recursos naturais, pois a sua exploração pode causar impactos ambientais, porque o material geralmente é retirado da natureza.

Desta maneira, com os valores e dados apresentados durante os ensaios no decorrer deste trabalho de pesquisa, foi demonstrado que é possível reaproveitar este tipo de resíduo industrial podendo incluí-lo na confecção do concreto com uma porcentagem adequada.

Os objetivos específicos foram efetuados, com todos os ensaios que foram realizados no decorrer desta pesquisa, caracterizando os agregados e os cavacos de aço, definindo seus dados como a sua granulometria, massa específica, massa unitária e absorção de água, dosando os materiais conforme a porcentagem de substituição do agregado miúdo pelo resíduo de cavaco de aço e confeccionando o concreto.

Portanto, o objetivo geral deste trabalho foi alcançado, pois foi concluído que até $15 \%$ o agregado miúdo pode ser substituído pelos cavacos de aço, sendo capaz de manter a resistência a compressão do concreto.

E foi demonstrado que é possível incluir este tipo de resíduo, proveniente da indústria Metal Mecânica e obter benefícios, diminuindo a utilização do agregado miúdo (recurso natural) por um agregado artificial (resíduo de cavacos de aço).

Deste modo, tem como proposta para trabalhos futuros, substituir uma porcentagem maior do que $20 \%$ do agregado miúdo pelos cavacos de aço, descobrindo os valores que podem ser obtidos com os ensaios. E outra sugestão é substituir o agregado miúdo e o agregado graúdo pelos cavacos de aço, desvendando se é possível alcançar bons resultados com este tipo substituição.

\section{REFERÊNCIAS}

ASSOCIAÇÃO BRASILEIRA DE NORMAS TÉCNICAS. NBR NM 248: Agregados Determinação da composição granulométrica. Rio de Janeiro, 2003. 
ASSOCIAÇÃO BRASILEIRA DE NORMAS TÉCNICAS. NBR 11578: Cimento Portland composto - Especificação. Rio de Janeiro, 1997.

ASSOCIAÇÃO BRASILEIRA DE NORMAS TÉCNICAS. NBR NM 52: Agregado miúdo Determinação da massa especifica e massa especifica aparente. Rio de Janeiro, 2009.

ASSOCIAÇÃO BRASILEIRA DE NORMAS TÉCNICAS. NBR NM 45: Agregados Determinação da massa unitária e do volume de vazios. Rio de Janeiro, 2006.

ASSOCIAÇÃO BRASILEIRA DE NORMAS TÉCNICAS. NBR NM 46: Agregados Determinação do material fino que passa através da peneira 75 um, por lavagem. Rio de Janeiro, 2003.

ASSOCIAÇÃO BRASILEIRA DE NORMAS TÉCNICAS. NBR 5738: Concreto Procedimento para moldagem e cura de corpos-de-prova. Rio de Janeiro, 2016.

ASSOCIAÇÃO BRASILEIRA DE NORMAS TÉCNICAS. NBR NM 30: Agregado miúdo Determinação da absorção de água. Rio de Janeiro, 2001.

ASSOCIAÇÃO BRASILEIRA DE NORMAS TÉCNICAS. NBR NM 53: Agregado graúdo Determinação de massa específica, massa específica aparente e absorção de água. Rio de Janeiro, 2009.

KRAEMER, Maria Elisabeth Pereira. A questão ambiental e os resíduos industriais. Itajaí, 2005? Disponível em: <http://www.amda.org.br/imgs/up/Artigo_25.pdf >. Acesso em: 08 mar. 2017.

NEVILLE, A. M. Propriedades do concreto. 5. ed. Porto Alegre: Bookman, 2016.

MACHADO, Álisson Rocha; ABRÃO, Alexandre Mendes; COELHO, Reginaldo Teixeira; DA SILVA, Márcio Bacci. Teoria da usinagem dos materiais. 3. ed. São Paulo: Blucher, 2015.

SANTOS, Sandro Cardoso; SALES, Wisley Falco. Aspectos tribológicos da usinagem dos materiais. São Paulo: Artliber Editora, 2007.

SOUZA, André João de. Processo de fabricação por usinagem: Parte 1. UFRGS, Universidade Federal do Rio Grande do Sul, Porto Alegre, 2011. Apostila. 